\title{
Loading deproteinized bovine bone with strontium enhances bone regeneration in rat calvarial critical size defects
}

\author{
Maurício Andrés Tinajero Aroni ${ }^{1}$ - Guilherme José Pimentel Lopes de Oliveira ${ }^{1}$ - Luís Carlos Spolidório ${ }^{2}$. \\ Ole Zoffmann Andersen ${ }^{3} \cdot$ Morten Foss $^{4} \cdot$ Rosemary Adriana Chiérici Marcantonio ${ }^{1} \cdot$ Andreas Stavropoulos $^{5}$ (iD)
}

Received: 23 October 2017 / Accepted: 17 August 2018 / Published online: 25 August 2018

(C) The Author(s) 2018

\begin{abstract}
Objective To evaluate the effect of grafting with strontium (Sr)-loaded deproteinized bovine bone (DBB) on bone healing in calvarial critical size defects (CSD) in rats.

Material and methods Two circular bone defects ( $5 \mathrm{~mm}$ in diameter) were created in the calvaria of 42 rats. One of the defects, randomly chosen, was grafted with (a) DBB, (b) DBB loaded with $19.6 \mu \mathrm{g} / \mathrm{g}$ of Sr (DBB/Sr1), or (c) DBB loaded with $98.1 \mu \mathrm{g} / \mathrm{g}$ of $\mathrm{Sr}(\mathrm{DBB} / \mathrm{Sr} 2)$. The other defect was left empty as negative control. Groups of seven animals from each of the groups were euthanized 15 and 60 days post-op. Bone healing in the CSD was evaluated by micro-CT and histology/histomorphometry and immunohistochemistry.

Results DBB/Sr2-grafted sites showed statistically significantly shorter radiographic residual defect length compared with DBB/ Sr1- and DBB-grafted sites, and with empty controls at 60 days. Further, the amount of new bone formation in the DBB/Sr1- and $\mathrm{DBB} / \mathrm{Sr} 2$-grafted sites was significantly higher compared with that in the DBB-grafted sites at 60 days. A larger number of DBB/ Sr1- and DBB/Sr2-grafted sites presented with no- or only limited to mild inflammation, compared with the DBB-grafted sites, especially at 60 days. Higher expression of osteocalcin was observed in DBB/Sr1- and DBB/Sr2-grafted sites as compared to DBB-grafted sites.

Conclusion Grafting with Sr-loaded DBB enhanced bone formation in CSD in rats, when compared with grafting with nonloaded DBB.

Clinical relevance Grafting with Sr-loaded DBB may enhance bone formation in bone defects.
\end{abstract}

Keywords Bone regeneration $\cdot$ Bone substitutes $\cdot$ Strontium $\cdot$ Histology $\cdot$ Micro-CT $\cdot$ Animal experiment

\section{Introduction}

Limited bone availability due to disease, trauma, or congenital conditions often impairs proper implant placement. A variety of approaches has been employed for increasing the

Andreas Stavropoulos

andreas.stavropoulos@mau.se

1 Department of Diagnosis and Surgery, School of Dentistry of Araraquara, Univ. Est. Paulista, Araraquara, Brazil

2 Department of Oral Pathology, School of Dentistry of Araraquara, Univ. Est. Paulista, Araraquara, Brazil

3 Elos Medtech Pinol A/S, Gørløse, Denmark

4 iNANO and Department of Physics and Astronomy, Science and Technology, Aarhus University, Aarhus, Denmark

5 Department of Periodontology, Faculty of Odontology, Malmö University, Carl Gustafs väg 34, SE-205 06 Malmö, Sweden available bone volume, primarily based on grafting of autogenous bone, bone substitutes, or growth factors, as mono-therapies or in combinations thereof. Autogenous bone is considered the "gold standard," since it provides the scaffold, cells, and growth factors needed for bone formation. However, autogenous bone grafting has limitations like donor site morbidity, unpredictable/large graft resorption, increased time and cost of treatment, and occasionally limited availability [1-3]; use of bone substitutes is, thus, common. Deproteinized bovine bone (DBB) is among the most widely used bone substitutes in dentistry; DBB is osteoconductive, i.e., provides a scaffold for new bone formation and facilitates space provision. Successful outcomes after DBB use, also on the long term, have been reported in numerous studies and for various indications, e.g., one- or two-stage maxillary sinus floor elevation procedures, lateral and vertical bone augmentation, and post-extraction alveolar ridge preservation $[1,2,4,5]$. 
Pre-clinical studies have indicated, however, that bone regeneration and remodeling in a bone defect filled solely with DBB is delayed and/or compromised [6-8]. On the other hand, addition of $\mathrm{AB}$ and/or bone promoting substances to DBB is shown to significantly improve the outcome in terms of bone formation and/or implant osseointegration [9-12]. For instance, it has been shown in a mini-pig maxillary sinus-lift model, that adding some $\mathrm{AB}$ to $\mathrm{DBB}$, for example, in a $25 \%: 75 \%$ ratio, is necessary to achieve a similar degree of osseointegration as achieved solely with $\mathrm{AB}$ [10]; while, DBB combined with recombinant human bone morphogenic protein 2 (rhBMP-2) results in a significantly larger amount of bone regeneration in a rat calvarial critical size defect (CSD) model, compared with grafting with only DBB [13].

In this context, a natural element shown to have a beneficial effect on bone is strontium (Sr), an alkaline earth metal with the atomic number 38. Sr has similar properties with calcium (Ca) - it is also located under $\mathrm{Ca}$ in the periodic system - and thus has the possibility to incorporate into the mineral phase of bone. Sr exerts both an anabolic effect on osteoblasts and a catabolic on osteoclasts $[14,15]$. Specifically, it increases differentiation of mesenchymal cells to osteoblasts via the Wnt/ $\beta$-catenin pathway, while it decreases osteoclastogenesis by increasing osteoprotegerin (OPG) and decreasing receptor activator of nuclear factor kappa-B ligand (RANKL) expression from osteoblasts [16]. Systemic administration of $\mathrm{Sr}$ (in the form of $\mathrm{Sr}$ ranelate - $\mathrm{SrR}$ ) has been shown to improve bone quality and reduces the risk of fractures both in females with postmenopausal osteoporosis and osteoporotic men [17, 18]. More recently, several experimental studies have shown promising results in terms of increased bone formation after $\mathrm{Sr}$ enrichment of various bone substitute materials, such as allogeneic bone [19], bioactive bioglass [20, 21], calciumsilicon ceramic [22], calcium phosphate [23, 24], and hydroxyapatite $[25,26]$. Furthermore, it was observed in recent experiments that Sr-loaded titanium implants presented significantly increased bone-to-implant contact, comparing to control implants [27-29]. Thus, another approach to enhance the bone regenerative potential of DBB may be to combine it with strontium (Sr).

The aim of the present study was to evaluate the effect of Sr-loaded DBB grafting on bone healing of calvarial CSD in rats.

\section{Material and methods}

\section{Animal care-surgical procedures}

The present study was approved by the commission of ethical use of animals at the School of Dentistry of Araraquara (07/ 2014) and is reported according to the ARRIVE guidelines with respect to relevant items [30].
Forty-two, 3-month-old (ca. 250-300 g) female rats (Rattus norvegicus, var. albinus, Holtzman) were used in this study. The animals were kept in pairs in purpose-build cages at the School of Dentistry of Araraquara (FOAr-UNESP), with 12-h light/dark light cycle at $21-25^{\circ} \mathrm{C}$, and with ad libitum access to rat-chow and water, during the entire experimental period. The animals were anesthetized with a combination of $0.8 \mathrm{ml} /$ $\mathrm{kg}$ ketamine hydrochloride (Francotar, Virbac do Brasil Ind. Com. Ltda., São Paulo, Brazil) and $0.4 \mathrm{ml} / \mathrm{kg}$ xylazine hydrochloride (Virbaxyl 2\%, Virbac do Brasil Ind. E Com. Ltda., São Paulo, Brazil). Subsequently, animals were fixed in prone position on the operating table, and their calvarias shaved and then disinfected using sterile gauze soaked in a $0.12 \%$ chlorhexidine solution. By means of a sagittal midline incision made on the scalp of the animal, the skin, muscles, and periosteum were elevated in layers, exposing the bone of the calvaria. A full thickness CSD was made on each of the parietal bones by means of a trephine drill (3i implantes do Brasil, São Paulo, Brazil) under constant saline irrigation. Defect dimensions were $5 \mathrm{~mm}$ in diameter and approximately $1.5 \mathrm{~mm}$ thick, corresponding to the thickness of the calvarial bone. Further, two perforations $0.5 \mathrm{~mm}$ wide were made $2 \mathrm{~mm}$ from the anterior and posterior margins of the defect, and were filled with gutta-percha to serve as a landmark during histology, indicating the center of the defect. One of the defects was filled with bone substitute (i.e., test), according to the group the animal was randomly allocated to, while the other defect remained empty as control. Test and control sites were alternated between right and left in subsequent animals to end up in a balanced number of right/left-grafted sites. Care was taken to avoid overfilling the defects or injuring the dura mater. Subsequently, the soft tissues were repositioned and sutured in layers using 4.0 Vicryl (Ethicon, Johnson \& Johnson, São José dos Campos, Brazil) for internal sutures and 4.0 silk (Ethicon, Johnson \& Johnson, São José dos Campos, Brazil) for external sutures. Upon completion of the surgical procedure, animals received a single dose of a combination of antibiotics for infection control (Pentabiótico veterinario pequeno porte, Zoetis Dodge, São Paulo, Brazil, s.c. $0.3 \mathrm{ml} / \mathrm{kg}$ ) and ketoprofen for pain control (Ketoflex; Mundo Animal, São Paulo, Brazil, IM: $0.03 \mathrm{ml} / \mathrm{g}$ ). Animals were euthanized with an overdose of anesthetic injection and the calvarias, including the overlying soft tissues, were harvested and fixed in $4 \%$ paraformaldehyde for $48 \mathrm{~h}$. Afterwards, samples were washed in water and stored in $70 \%$ ethanol at room temperature.

\section{Experimental groups}

The animals were divided in three equally sized groups, receiving either DBB or DBB loaded by adsorption with $19.6 \mu \mathrm{g} / \mathrm{g}$ or $98.1 \mu \mathrm{g} / \mathrm{g} \mathrm{Sr}$, in the form of $\mathrm{SrCl}_{2} \cdot 6 \mathrm{H}_{2} \mathrm{O}$ (Sigma-Aldrich Denmark A/S, Copenhagen, Denmark) (DBB/Sr1 and $\mathrm{DBB} / \mathrm{Sr} 2$, respectively). More specifically, 
loading of the DBB particles with Sr was performed by adding either $1.6 \mathrm{~mL}$ of $140 \mu \mathrm{M}$ or $700 \mu \mathrm{M} \mathrm{SrCl}$, dissolved in ultrapure water, to $1 \mathrm{~g}$ of DBB. The non-loaded DBB was prepared by adding $1.6 \mathrm{~mL}$ of ultrapure water. Subsequently, the samples were left at room temperature for $48 \mathrm{~h}$ before being frozen at $-80{ }^{\circ} \mathrm{C}$ followed by freeze-drying. Afterwards, each sample was distributed into smaller glass vials, with $200 \mathrm{mg}$ in each, before, finally, a thermal treatment for a period of $12 \mathrm{~h}$. For each of the three experimental groups, seven animals were sacrificed at day 15 and seven at day 60 , after completing the grafting procedure.

\section{Micro-CT}

The calvarias were scanned with Skyscan 1176 (SkyScan, Aartselaar, Belgium) with the following parameters: Camera Pixel: 12.45 ; x-ray tube potential: $65 \mathrm{kVP}$, x-ray intensity: $385 \mu \mathrm{A}$, integration time: $300 \mathrm{~ms}$, filter: Al-1 mm, and voxel size: $18 \mu \mathrm{m}$. Generated images were reconstructed, reoriented spatially, and analyzed using a purpose-built software (NRecon/DataViewer/CTan, Skyscan, Aartselaar, Belgium). A circular region of interest (ROI) with $5 \mathrm{~mm}$ in diameter corresponding to the defect was traced in each of 40 axial equidistant sections, stretching from the cranial to the dural boundaries of the cranium (i.e., encompassing the entire defect thickness) (Fig. 1a). Using a standardized threshold of 55-255 grayscale, bone regeneration within the ROI was assessed by estimating (1) the radiographic residual defect length (R-RDL): average of the distance (in $\mathrm{mm}$ ) between the new bone margins measured at the center of the original defect, in the sagittal and coronal plane, using only the first dural section within the ROI (Fig. 1b); and (2) the radiographic mineralized tissue fill (R-MTF): new bone formation and DBB volume expressed as \% of the ROI. The analysis was
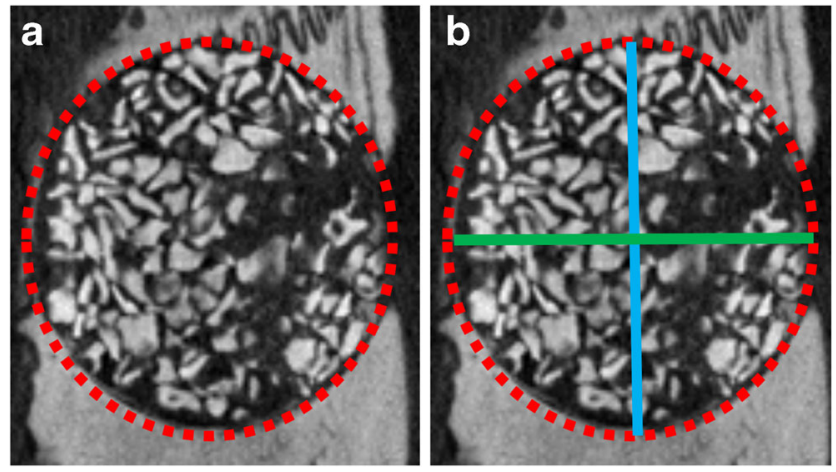

Fig. 1 a In each of $40 \mu \mathrm{CT}$ sections comprising the entire bone defect volume, a circular region of interest (ROI) was identified (dotted red line). Radiographic mineralized tissue fill, i.e., new bone formation and DBB volume expressed as \% of the ROI, was assessed using a standardized threshold. b Radiographic residual defect length was defined as the average of the distance (in $\mathrm{mm}$ ) between the new bone margins measured at the center of the original defect, in the sagittal and coronal plane (blue and green lines respectively) performed by a trained examiner, who was blinded to the experimental groups (MATA).

\section{Histology-histomorphometry}

After micro-CT scanning, the samples were processed for decalcified histological analysis following standard methods. Sixteen paraffin $5-\mu \mathrm{m}$ thick sections parallel to the sagittal plane were obtained from central aspects of the defect and stained with hematoxylin-eosin (HE). Two sections, $40 \mu \mathrm{m}$ apart, with the first one chosen at random among the first eight sections, were used for analysis. The images were viewed with an incandescent light microscope (Diastar, Leica Reichert \& Jung products, Wetzlar, Germany) at $\times 25$ magnification and captured by a camera connected to a computer (Leica Microsystems DFC -300 -FX; Leica Reichert Jung \& Products, Wetzlar, Germany). The newly formed bone, any inflammatory reactions around the DBB particles, vessel formation, and qualitative aspects of the connective tissue within the defect were assessed by an experienced pathologist blinded to the groups (LCS).

The margins of the original defect were identified and the relative tissue composition (i.e., \% of new mineralized bone and DBB) inside a rectangular ROI, representing the original defect area, was assessed using an image analysis software (Image J, Jandel Scientific, San Rafael, CA, USA), by an experienced examiner blinded to the groups (MATA). Furthermore, the histological level of inflammation was assessed using a six-point scale: $0=$ absent, $1=$ minimal, $2=$ slight, 3 = moderate, $4=$ marked, $5=$ severe [31].

\section{Immunohistochemistry}

Histological sections prepared per standard protocols for immunohistochemistry were incubated with primary antibodies for osteocalcin (OCN) (Novus Biologicals, Littleton, USA) and transforming growth factor $\beta 1$ (TGF- $\beta 1)$ (R\&D Systems, Minneapolis, USA) for $16 \mathrm{~h}$. Then, sections were treated with the avidin-biotin-peroxidase complex (ABC) using the ABC Staining System kit (Santa Cruz Biotechnology, Inc., Santa Cruz, USA) and counterstained with Carrazi's hematoxylin. Sections treated with $1 \%$ PBS were used as negative controls. A four-scale index was implemented to assess the extent of staining (i.e., absent, mild, moderate, or strong) [32] in three regions: (1) in the middles of the CSD and (2) two regions at the edges of the CSD at a magnification of $\times 200$ by a trained examiner blinded to the groups (GPO).

\section{Statistics}

Normality of the $\mu \mathrm{CT}$ and histomorphometric data was confirmed by the Kolmogorov-Smirnov test $(p>0.05)$. One- 
way ANOVA with Tukey post hoc test was used for comparisons among groups at 15 and 60 days, while non-paired $t$ tests were used for intragroup comparisons between 15 and 60 days. Further, a paired $t$ test was used to compare grafted and non-grafted defects in each experimental group. Immunohistochemistry data were analyzed with the nonparametric test of Kruskal-Wallis with Dunn post hoc test. The Graphpad Prism 5.0 software (San Diego, CA, USA) was used for all statistical tests, with $p$ set at 0.05 .

Sample size calculation was based on data from one study evaluating the effect of various bone substitute material in bone regeneration in CSD in rats, using a similar histomorphometric evaluation [33]. In this study, the minimum average difference in bone formation observed among the various biomaterials was $7.3 \%$, with a standard deviation of 3.75. Using ANOVA and considering a power $\beta$ of 0.8 and an $\alpha$ of 0.05 , a minimum sample size of seven animals per group was required.

\section{Results}

All animals recovered well from the operation, and there was nothing remarkable regarding the postoperative healing period.

\section{Micro-CT}

R-RDL was in general larger at the 15-day compared with the 60-day observation period in all three test groups and in their respective empty controls (Fig. 2). At 60 days, R-RDL was significantly shorter in the $\mathrm{DBB} / \mathrm{Sr} 2$-grafted sites compared
DBB
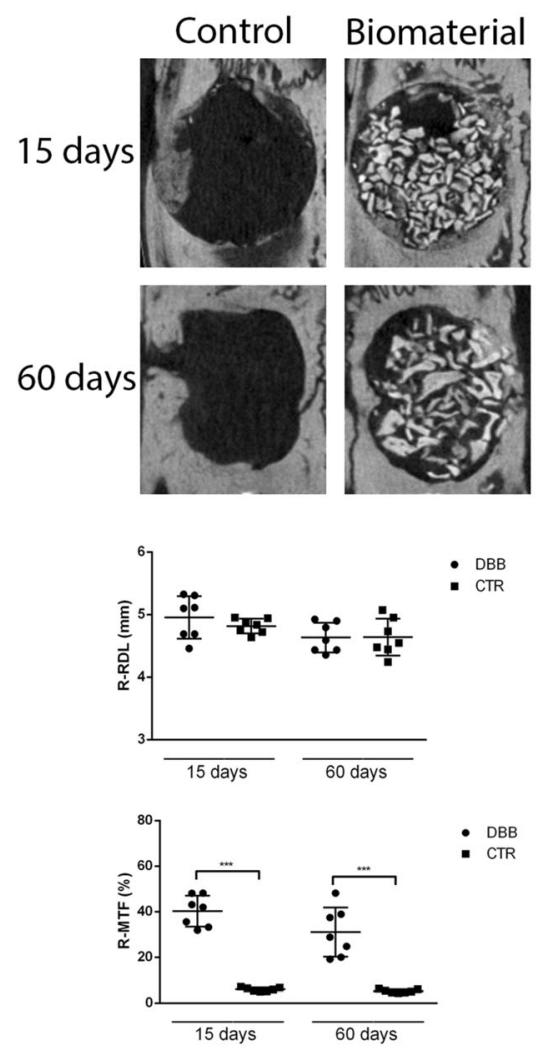

$\mathrm{DBB} / \mathrm{Sr} 1$
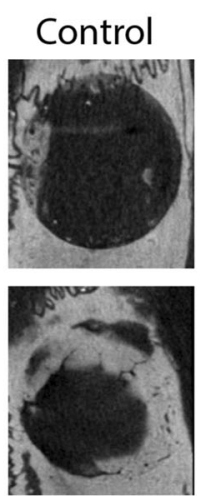
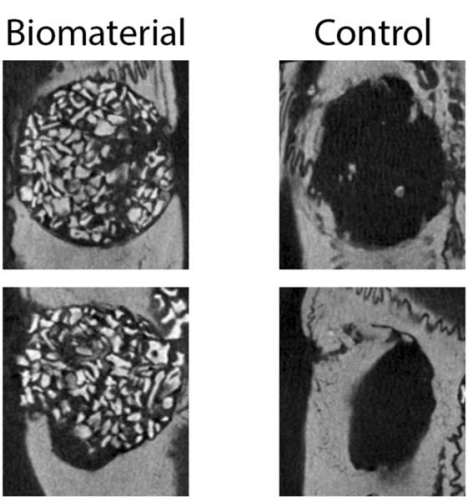

$\mathrm{DBB} / \mathrm{Sr} 2$
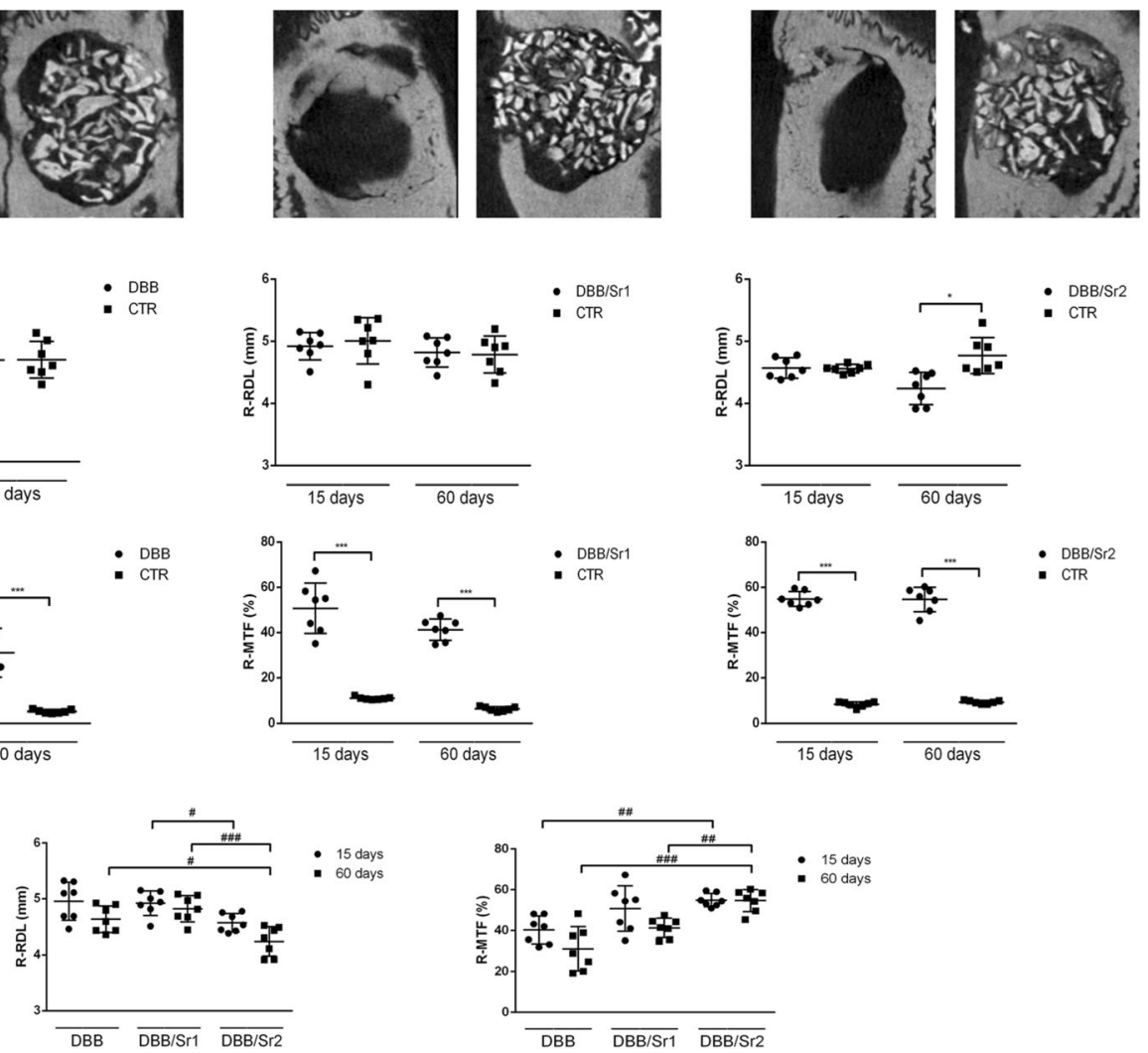

Fig. 2 A panel with representative $\mu \mathrm{CT}$ sections from each grafting group and its respective empty controls at 15 - and 60 days post-op and charts from the radiographic analysis. The shortest radiographic residual defect length (R-RDL) and the largest radiographic mineralized tissue fill (R$\mathrm{RTF}$ ), on average, was observed in the $\mathrm{DBB} / \mathrm{Sr} 2$ group at 60 days. Triple

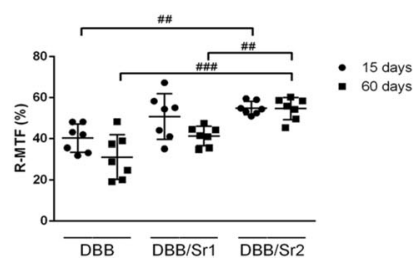

asterisks indicate intragroup statistically significant differences at $p<0.001$ - paired $t$ test. A single asterisk, double asterisks, and triple asterisks indicate intergroup statistically significant differences at $p<0.05,<0.01$, and $<0.001$ respectively-one-way ANOVA complemented by Tukey 
with DBB/Sr1- and DBB-grafted sites and to its empty control; however, R-RDL was never $<4 \mathrm{~mm}$ in any of the groups.

All grafted sites presented with significantly larger R-MTF compared with their respective empty controls (Fig. 2). DBB/ Sr2-grafted sites presented significantly larger R-MTF compared with DBB-grafted sites at 15 days and compared with both DBB- and DBB/Sr1-grafted sited at 60 days.

\section{Histology-histomorphometry}

In empty control sites, at 15 days postoperatively, the defect space was filled with slender loose connective tissue, consisting of collagen fiber bundles intermingled with capillaries of varying size, elongated fibroblasts, and a large number of mononuclear leukocytes. New woven bone, rich in osteocytes, was observed only at the edges of the defect; a single layer of cuboidal osteoblasts was observed covering the newly formed bone in proximity to the connective tissue. At 60 days postsurgically, the collagen fiber bundles had increased in thickness and were interspersed with fibroblasts with fusiform morphology, while reduced number of capillaries and mononuclear leukocytes were observed. New bone formation at the edges of the defect had slightly progressed, but osteoblasts appeared reduced in numbers and more flattened (Fig. 3).

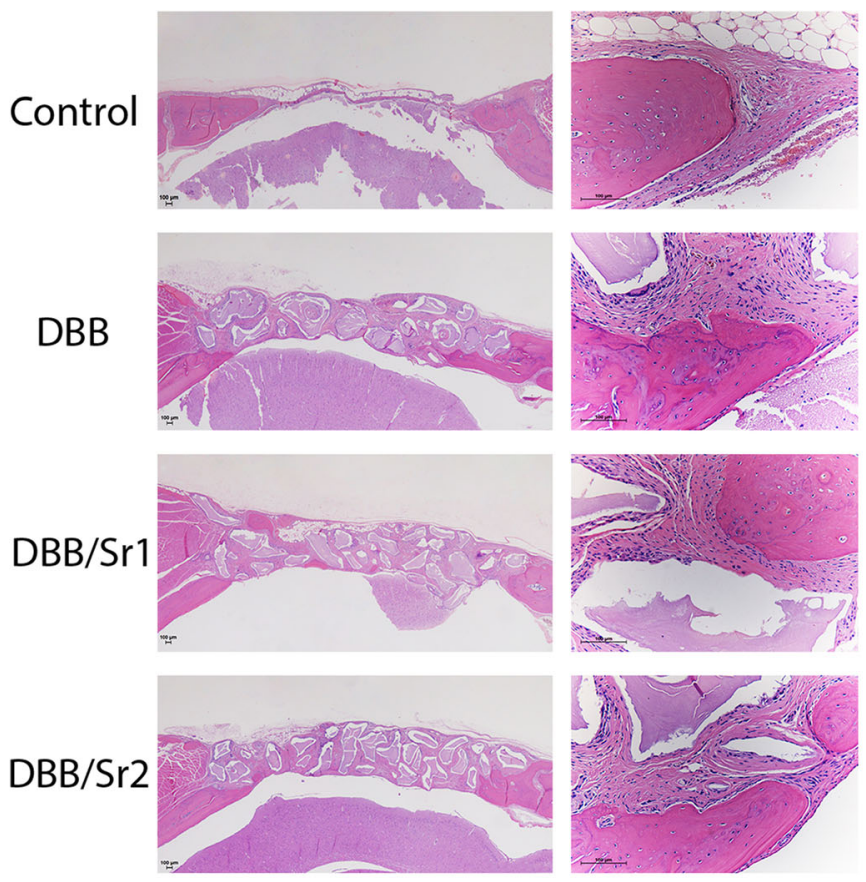

Fig. 3 A panel with representative histological images from each treatment group at 60 days post-op and charts from the histomorphometric analysis. Left column shows the entire defect $(\times 25)$; right column shows a higher magnification $(\times 200)$ of the dotted areas. In general, new bone formation was restricted at the edges of the CSD, irrespective treatment group. New bone formation extending towards the middle of the defect was only rarely
In the DBB-grafted sites, irrespective group or experimental period, the defects were filled with biomaterial particles inside a loose connective tissue stroma, similar with that observed in the empty control sites (Fig. 3). Graft particles in $\mathrm{DBB} / \mathrm{Sr} 1$ and $\mathrm{DBB} / \mathrm{Sr} 2$ sites presented with a more irregular surface pattern, compared with those in DBB sites, and a variable number of giant cells was observed in the vicinity the DBB particles. However, it seemed that defects grafted with $\mathrm{DBB} / \mathrm{Sr} 1$ and $\mathrm{DBB} / \mathrm{Sr} 2$ presented a fewer number of inflammatory cells in the vicinity of the DBB particles. Irrespective of observation period, limited amount of new bone formation, mostly at the edge of the defects and occasionally in contact with neighboring DBB particles, was observed in the grafted sites. In few instances, bone formation had advanced towards the center of the defect - always as a rather slender sprout - mostly at the aspect of the defect towards the dura matter (Fig. 3).

New bone formation in the grafted defects was always statistically significantly lower compared to their corresponding empty control defects; grafted sites were never found to have $>10 \%$ new bone. On the other hand, empty control sites were almost always found to have $>15 \%$ new bone. However, in the DBB/Sr1- and DBB/Sr2-grafted sites, the amount of new bone formation was significantly higher compared to the DBB-grafted sites at 60 days (Fig. 3). No differences among groups regarding the amount of graft particles were
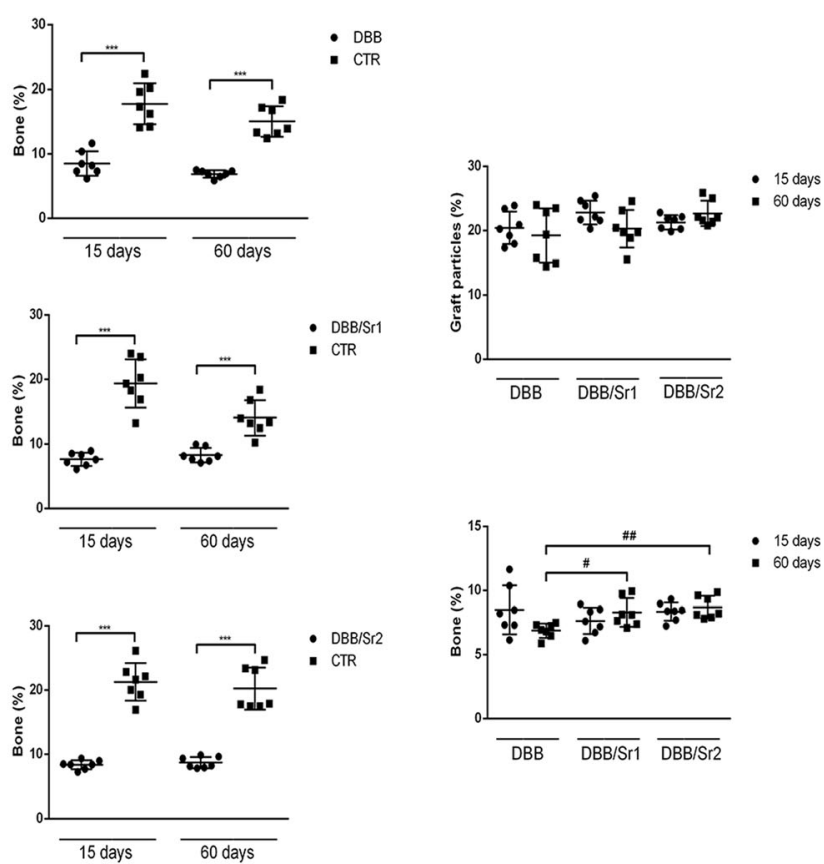

observed (DBB/Sr1 in this panel), and this was not associated with any specific grafting group. New bone formation in contact with the graft particles was not common. Triple asterisks indicate intragroup statistically significant differences at $p<0.001$ - paired $t$ test. A single asterisk and double asterisks indicate intergroup statistically significant differences at $p<0.05$ and $<0.01$ respectively — one-way ANOVA complemented by Tukey 
observed at both observation periods. Further, no remarkable reduction in the amount of graft particles was observed from 15 to 60 days, and graft particles always occupied about $20 \%$ of the defect space (Fig. 3). Furthermore, a larger number of $\mathrm{DBB} / \mathrm{Sr} 1$ - and $\mathrm{DBB} / \mathrm{Sr} 2$-grafted sites presented with no- or only limited to mild inflammation, compared with the DBBgrafted sites, especially at 60 days; the difference between $\mathrm{DBB} / \mathrm{Sr} 2$ and $\mathrm{DBB}$ groups was statistically significant (Fig. 4).

\section{Immunohistochemistry}

In general, expression of TGF $\beta 1$ and OCN was not pronounced in any of the groups or at any of the two observation periods (Fig. 5). TGF $\beta 1$ was expressed both in the new bone tissue and in the connective tissue observed inside the defect, while moderate TGF $\beta 1$ expression was observed in connection with DBB particles in all grafted groups. OCN was primarily expressed in the new bone formed at the edges of the CSD, while moderate OCN expression was observed also in connection with graft particles in the $\mathrm{DBB} / \mathrm{Sr} 1$ and $\mathrm{DBB} / \mathrm{Sr} 2$ groups, but never in the DBB group.

\section{Discussion}

The results of the present study showed that grafting of $\mathrm{Sr}-$ loaded DBB enhances bone formation in CSD in rats, when compared with grafting of non-loaded DBB. Particularly, sites grafted with DBB loaded by adsorption with $98.1 \mu \mathrm{g} / \mathrm{g} \mathrm{SrCl}_{2}$ showed statistically significantly smaller residual defect length and larger amounts of new bone after 60 days of healing, compared with non-loaded DBB-grafted sites.

Thus, this study supports previously published pre-clinical in vivo reports, where various Sr-loaded bone substitute materials were shown to enhance bone formation in a variety of models, including the calvarial CSD in rats as herein [19,21, 24, 26]. For instance, $5 \mathrm{~mm}$ of CSD grafted with Sr-loaded

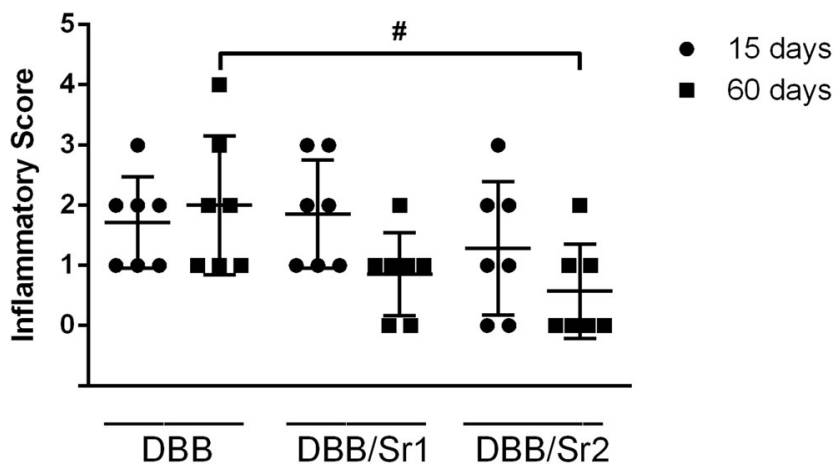

Fig. 4 A chart showing the histological level of inflammation in the three groups, as assessed by a six-point scale. A single asterisk indicates intergroup statistically significant difference at $p<0.05$-Kruskall-Wallis complemented by Dunn bioglass particles showed significantly larger amounts of new bone compared with defects grafted with non-loaded bioglass or with non-grafted controls, after 8 weeks of healing [21]. In another study, using the same model, defects grafted with a collagen-hydroxyapatite-Sr construct showed increased radiographic bone density and bone formation compared to defects grafted with the collagen-hydroxyapatite construct without $\mathrm{Sr}$ or non-grafted controls at 12 weeks [26]. In yet another study, circular, but this time partial thickness, calvarial defects in rats grafted with BMP-2-loaded DBB showed 30-50\% more new bone compared to DBB-grafted defects, as early as 2 weeks following the surgical procedure [13]. Further, DBB in combination with platelet-rich-plasma (PRP) showed 2-3 times more bone formation in full thickness calvarial CSD defects in rabbits over a period of 2 to 4 months [34]. The calvarial CSD was chosen herein to screen for the potential of $\mathrm{Sr}$ loaded DBB to enhance bone regeneration per se. The CSD is a well characterized experimental model, i.e., there is information regarding expected healing outcomes in empty untreated sites, depending on defect dimensions and observation times; it is perhaps the most widely used pre-clinical in vivo model for screening biomaterials for their potential to enhance bone formation [35]. The symmetrical morphology of the defect facilitates a straightforward analysis, including unbiased radiographic and histological evaluation. Usually, observation periods up to 8 weeks are used, as it has been demonstrated that bone formation in empty calvarial CSD reaches a plateau during this period, with only minimal bone formation at longer observation periods [36]. In this context, the present results support the concept that combining DBB with an osteopromotive substance, it enhances the outcome of DBB grafting in terms of bone regeneration.

The mechanism by which $\mathrm{Sr}$ is promoting bone formation is not completely understood, but appears to exert both an anabolic effect on osteoblasts and a catabolic on osteoclasts $[14,15]$. One proposed mechanism is that $\mathrm{Sr}$ enhances differentiation of non-differentiated cells to osteoblasts through upregulation of the promoters b-catenin and frizzled eight [FZD8], through downregulation of the suppressor protein phosphatase 2A [PP2A] of the $\mathrm{Wnt} / \beta$-catenin pathway [26], and through the activation of ERK1/2 and p38 MAPK signaling pathway [37]. Another proposed mechanism is that it enhances osteoblast activity via the activation of the cell-surface $\mathrm{G}$ protein-coupled $\mathrm{Ca}$-sensing receptor (CaSR), which plays role in the regulation of $\mathrm{Ca}$ levels via controlling its influx [38]; inhibition of CaSR has indeed been shown to reduce Sr-induced osteoblastic differentiation of murine osteoblasts [39]. In the present study, sites grafted with Sr-loaded DBB presented with no- or only limited to mild inflammation, compared with those grafted with DBB. A previous study has shown that treatment of human PDL fibroblasts with Sr has the possibility to suppress expression of the pro-inflammatory cytokine IL-6 [40], while recent evidence suggests that IL-6 
Fig. 5 A panel with representative histological images

from each grafted group at

15 days post-op and charts from

the immunohistochemical

analysis. Increased OCN

expression, indicated by the

intense brown staining was

observed around the graft

particles in the DBB/Sr1 and

$\mathrm{DBB} / \mathrm{Sr} 2$ groups, but not in the

DBB group. No remarkable

differences could be observed

among the groups regarding

TGF $\beta 1$ expression. A single

asterisk indicates intergroup

statistically significant differences

at $p<0.001$-Kruskall-Wallis

complemented by Dunn
TGF $\beta 1$
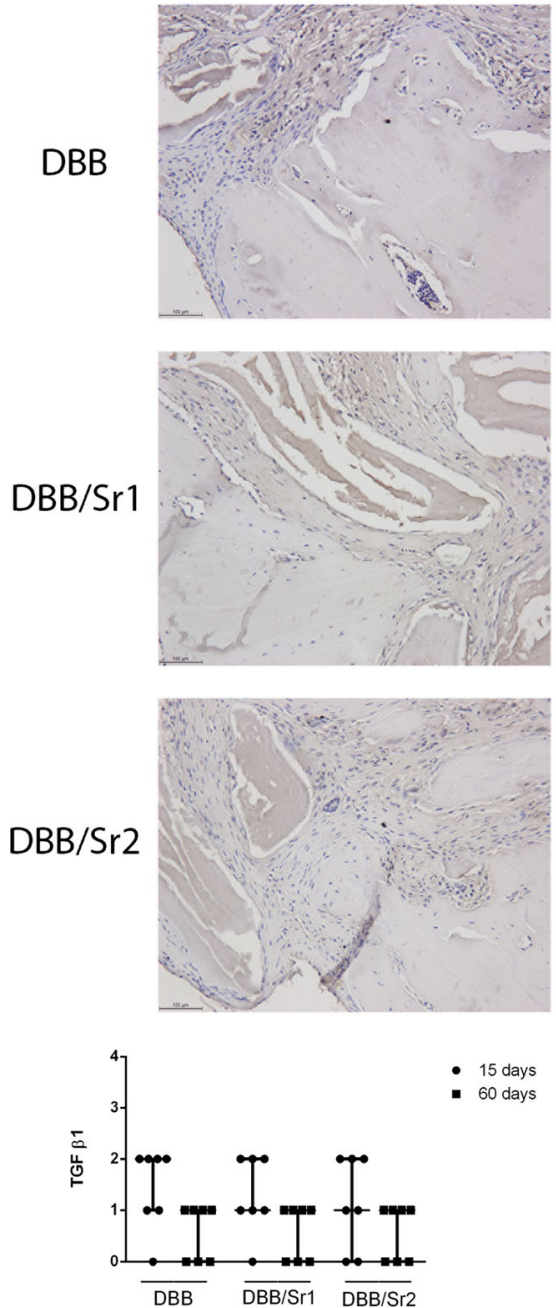

- 15 days

- 60 days
OCN
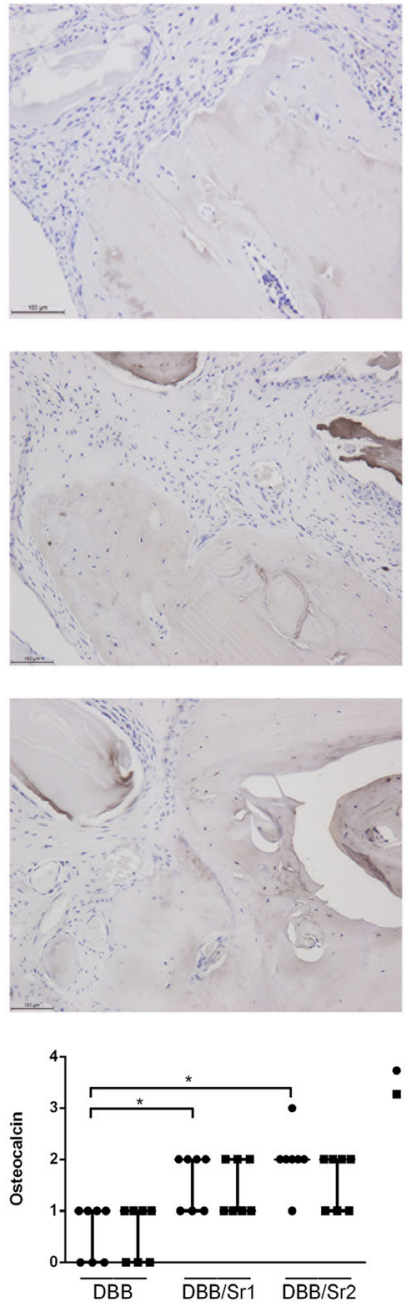

may influence negatively bone remodeling, although the mechanisms are yet not completely elucidated [41]. It seems thus interesting to explore in future studies, the possible impact of any anti-inflammatory action of $\mathrm{Sr}$ on bone formation. In this context, it was intended in the present study that grafting with a Sr-loaded bone substitute would lead to enhanced bone formation compared with non-grafted empty defects. However, the amount of regenerated bone in the empty control defects was always larger as compared to their respective grafted sites. Similar results, in terms of reduced bone formation in DBB-grafted sites, have been previously reported using various animal platforms, including the calvaria CSD in rats [6-8, 34, 42]. For example, DBB grafting in CSD in rats showed about $10 \%$ new bone fill after 6 weeks, while empty controls presented about $20 \%$ new bone fill [42]. In studies using another experimental model, Teflon hemispherical capsules grafted with DBB and stabilized on the lateral aspect of the ramus in rats were consistently filled with limited amounts of new bone; in contrast, control capsules that were left empty at placement presented always significantly larger amounts of new bone [6-8]. Since Sr-loaded DBB sites did not show a dramatic effect in terms of bone regeneration in the present study, it can be claimed that the use of DBB may have compromised any possible positive effect of $\mathrm{Sr}$.

On the other hand, one cannot exclude the possibility that the limited bone formation observed in the Sr-loaded DBB sites may be due to inadequate $\mathrm{Sr}$ doses. Indeed, a dose-related effect seemed apparent herein, as the sites grafted with the high-dose $\mathrm{DBB} / \mathrm{Sr} 2$ showed better results than those grafted with the lowdose DBB/Sr1. However, the current study was not designed as a dose response study; rather, this study was simply a first attempt to assess whether there is any potential for $\mathrm{Sr}$ to enhance bone regeneration per se when delivered locally in a DBBgrafted site, and thus only two doses where tested. The concentration used for the $\mathrm{DBB} / \mathrm{Sr} 1$ group was determined based on the plasma levels of Sr observed in humans undergoing treatment for osteoporosis with systemic administration of strontium Ranelate (SrR), where for the standard daily dose of SrR 
( $2 \mathrm{~g} /$ day) are in the range of $120-140 \mu \mathrm{M}$. The concentration of Sr used for the DBB/Sr2-loaded group was, however, chosen arbitrarily. It may be expected that a major part of the Sr deposited on the DBB surface is readily released when the particles come in contact with plasma, during the very early phases of healing; thus, by increasing the initial $\mathrm{Sr}$ content, it was aimed to maintain an effective $\mathrm{Sr}$ concentration inside the wound, over a longer period of time [43]. In retrospect, it appears that the concentration used for the $\mathrm{DBB} / \mathrm{Sr} 1$ group was too low to maintain an effective $\mathrm{Sr}$ dose over a longer period of time and obtain a measurable effect, while the higher concentration used for the $\mathrm{DBB} / \mathrm{Sr} 2$ group, indeed enhanced bone regeneration herein, albeit at a moderate extent; it is thus interesting to evaluate the possible effect of DBB grafting, when loaded with even higher concentrations of $\mathrm{Sr}$. In this context, the possible mechanism of Sr retention by DBB should be considered. Beyond simple surface deposition of $\mathrm{SrCl}_{2}$ on the graft particles, there is the possibility of some extent of $\mathrm{Ca}$ ion substitution with $\mathrm{Sr}$ in the bone apatite crystals [44]. Indeed, moderate OCN expression was observed at the surface of Sr-loaded DBB particles at both observation periods, but not at the non-loaded DBB particles. Such a mechanism might function to retain some of the $\mathrm{Sr}$ on the DBB surface for extended periods of time - compared to the readily soluble surface deposited $\mathrm{SrCl}_{2}$ salt $—$ and thereby facilitate sustained release. Detailed characterization of DBB following Sr loading and evaluation of $\mathrm{Sr}$ release profile appears thus necessary in future studies.

In the present study, loading of DBB with Sr did not alter the resorption profile of this material. Previous reports have shown that Sr-loaded biomaterial scaffolds exhibited increase resorption/dissolution comparing with uncoated ones [21, 22]. For instance, a calcium-silicon ceramic [22] and a mesoporous bioactive glass scaffold [21] were more readily resorbed when loaded with Sr. Although DBB was originally marketed as a resorbable bone substitute, long-term animal experiments [8, $45]$ and human histological reports [46, 47] have established that it is largely non-resorbing and, obviously, Sr loading herein did not make the material more soluble, since this was performed by adsorption, i.e., Sr was deposited on the surface of the particles and was not incorporated within the material, as in the reports mentioned above [21,22].

In conclusion, grafting with Sr-loaded DBB enhanced bone formation in calvarial CSD in rats, when compared with grafting with non-loaded DBB. Further studies should evaluate different doses and/or loading methods.

Acknowledgments The authors would like to thank the laboratory technicians Leandro Alves dos Santos and Ana Claudia Gregolin Costa Miranda for their support.

Funding The work was supported primarily by the institutions of the authors and in part by ASTI (no. 1382-00053B), a research consortium co-financed from the Danish Innovation Foundation. DBB was provided free of charge from Geistlich Pharma AG, Wohlhusen, Switzerland.

\section{Compliance with ethical standards}

Conflict of interest The authors declare that they have no conflict of interest.

Ethical approval The present study was approved by the Commission of ethical use of animals at the School of Dentistry of Araraquara (07014) and is reported according to the ARRIVE guidelines with respect to relevant items.

Informed consent For this type of study, formal consent is not required.

Open Access This article is distributed under the terms of the Creative Commons Attribution 4.0 International License (http:// creativecommons.org/licenses/by/4.0/), which permits unrestricted use, distribution, and reproduction in any medium, provided you give appropriate credit to the original author(s) and the source, provide a link to the Creative Commons license, and indicate if changes were made.

\section{References}

1. Merli M, Moscatelli M, Mariotti G, Rotundo R, Nieri M (2013) Autogenous bone versus deproteinised bovine bone matrix in 1stage lateral sinus floor elevation in the severely atrophied maxilla: a randomised controlled trial. Eur J Oral Implantol 6(1):27-37

2. Lutz R, Berger-Fink S, Stockmann P, Neukam FW, Schlegel KA (2015) Sinus floor augmentation with autogenous bone vs. a bovine-derived xenograft - a 5-year retrospective study. Clin Oral Implants Res 26(6):644-648. https://doi.org/10.1111/clr.12352

3. Spin-Neto R, Stavropoulos A, Coletti FL, Pereira LA, Marcantonio E Jr, Wenzel A (2015) Remodeling of cortical and corticocancellous fresh-frozen allogeneic block bone grafts-a radiographic and histomorphometric comparison to autologous bone grafts. Clin Oral Implants Res 26(7):747-752. https://doi.org/10. 1111/clr. 12343

4. Hurzeler MB, Kirsch A, Ackermann KL, Quinones CR (1996) Reconstruction of the severely resorbed maxilla with dental implants in the augmented maxillary sinus: a 5-year clinical investigation. Int J Oral Maxillofac Implants 11(4):466-475

5. Kotsakis GA, Salama M, Chrepa V, Hinrichs JE, Gaillard P (2014) A randomized, blinded, controlled clinical study of particulate anorganic bovine bone mineral and calcium phosphosilicate putty bone substitutes for socket preservation. Int J Oral Maxillofac Implants 29(1):141-151. https://doi.org/10.11607/jomi.3230

6. Stavropoulos A, Kostopoulos L, Mardas N, Nyengaard JR, Karring $\mathrm{T}$ (2001) Deproteinized bovine bone used as an adjunct to guided bone augmentation: an experimental study in the rat. Clin Implant Dent Relat Res 3(3):156-165

7. Stavropoulos A, Kostopoulos L, Nyengaard JR, Karring T (2003) Deproteinized bovine bone (Bio-Oss) and bioactive glass (Biogran) arrest bone formation when used as an adjunct to guided tissue regeneration (GTR): an experimental study in the rat. J Clin Periodontol 30(7):636-643

8. Stavropoulos A, Kostopoulos L, Nyengaard JR, Karring T (2004) Fate of bone formed by guided tissue regeneration with or without grafting of Bio-Oss or Biogran. An experimental study in the rat. J Clin Periodontol 31(1):30-39

9. Huh JB, Yang JJ, Choi KH, Bae JH, Lee JY, Kim SE, Shin SW (2015) Effect of rhBMP-2 immobilized anorganic bovine bone matrix on bone regeneration. Int J Mol Sci 16(7):16034-16052. https:// doi.org/10.3390/ijms160716034 
10. Jensen T, Schou S, Gundersen HJ, Forman JL, Terheyden H, Holmstrup P (2013) Bone-to-implant contact after maxillary sinus floor augmentation with Bio-Oss and autogenous bone in different ratios in mini pigs. Clin Oral Implants Res 24(6):635-644. https:// doi.org/10.1111/j.1600-0501.2012.02438.x

11. Jensen T, Schou S, Stavropoulos A, Terheyden H, Holmstrup P (2012) Maxillary sinus floor augmentation with Bio-Oss or BioOss mixed with autogenous bone as graft in animals: a systematic review. Int J Oral Maxillofac Surg 41(1):114-120. https://doi.org/ 10.1016/j.ijom.2011.08.010

12. Torres J, Tamimi F, Martinez PP, Alkhraisat MH, Linares R, Hernandez G, Torres-Macho J, Lopez-Cabarcos E (2009) Effect of platelet-rich plasma on sinus lifting: a randomized-controlled clinical trial. J Clin Periodontol 36(8):677-687. https://doi.org/10. 1111/j.1600-051X.2009.01437.x

13. Schwarz F, Ferrari D, Sager M, Herten M, Hartig B, Becker J (2009) Guided bone regeneration using rhGDF-5- and rhBMP-2coated natural bone mineral in rat calvarial defects. Clin Oral Implants Res 20(11):1219-1230. https://doi.org/10.1111/j.16000501.2009.01796.x

14. Gentleman E, Fredholm YC, Jell G, Lotfibakhshaiesh N, O'Donnell MD, Hill RG, Stevens MM (2010) The effects of strontiumsubstituted bioactive glasses on osteoblasts and osteoclasts in vitro. Biomaterials 31(14):3949-3956. https://doi.org/10.1016/j. biomaterials.2010.01.121

15. Marie PJ, Felsenberg D, Brandi ML (2011) How strontium ranelate, via opposite effects on bone resorption and formation, prevents osteoporosis. Osteoporosis international: a journal established as result of cooperation between the European Foundation for Osteoporosis and the National Osteoporosis Foundation of the USA 22(6):1659-1667. https://doi.org/10.1007/s00198-010-13690

16. Peng S, Liu XS, Huang S, Li Z, Pan H, Zhen W, Luk KD, Guo XE, Lu WW (2011) The cross-talk between osteoclasts and osteoblasts in response to strontium treatment: involvement of osteoprotegerin. Bone 49(6):1290-1298. https://doi.org/10.1016/j.bone.2011.08. 031

17. Giusti A, Bianchi G (2015) Treatment of primary osteoporosis in men. Clin Interv Aging 10:105-115. https://doi.org/10.2147/CIA. S44057

18. Reginster JY, Felsenberg D, Boonen S, Diez-Perez A, Rizzoli R, Brandi ML, Spector TD, Brixen K, Goemaere S, Cormier C, Balogh A, Delmas PD, Meunier PJ (2008) Effects of long-term strontium ranelate treatment on the risk of nonvertebral and vertebral fractures in postmenopausal osteoporosis: results of a five-year, randomized, placebo-controlled trial. Arthritis Rheum 58(6):16871695. https://doi.org/10.1002/art.23461

19. Zhao Y, Guo D, Hou S, Zhong H, Yan J, Zhang C, Zhou Y (2013) Porous allograft bone scaffolds: doping with strontium. PLoS One 8(7):e69339. https://doi.org/10.1371/journal.pone.0069339

20. Newman SD, Lotfibakhshaiesh N, O'Donnell M, Walboomers XF, Horwood N, Jansen JA, Amis AA, Cobb JP, Stevens MM (2014) Enhanced osseous implant fixation with strontium-substituted bioactive glass coating. Tissue Eng Part A 20(13-14):1850-1857. https://doi.org/10.1089/ten.TEA.2013.0304

21. Zhao S, Zhang J, Zhu M, Zhang Y, Liu Z, Tao C, Zhu Y, Zhang C (2015) Three-dimensional printed strontium-containing mesoporous bioactive glass scaffolds for repairing rat critical-sized calvarial defects. Acta Biomater 12:270-280. https://doi.org/10.1016/j. actbio.2014.10.015

22. Zreiqat H, Ramaswamy $\mathrm{Y}, \mathrm{Wu} \mathrm{C}$, Paschalidis A, Lu Z, James B, Birke O, McDonald M, Little D, Dunstan CR (2010) The incorporation of strontium and zinc into a calcium-silicon ceramic for bone tissue engineering. Biomaterials 31(12):3175-3184. https://doi.org/ 10.1016/j.biomaterials.2010.01.024
23. Kang P, Xie X, Tan Z, Yang J, Shen B, Zhou Z, Pei F (2015) Repairing defect and preventing collapse of femoral head in a steroid-induced osteonecrotic of femoral head animal model using strontium-doped calcium polyphosphate combined BM-MNCs. J Mater Sci Mater Med 26(2):80. https://doi.org/10.1007/s10856015-5402-x

24. Thormann U, Ray S, Sommer U, Elkhassawna T, Rehling T, Hundgeburth M, Henss A, Rohnke M, Janek J, Lips KS, Heiss C, Schlewitz G, Szalay G, Schumacher M, Gelinsky M, Schnettler R, Alt V (2013) Bone formation induced by strontium modified calcium phosphate cement in critical-size metaphyseal fracture defects in ovariectomized rats. Biomaterials 34(34):8589-8598. https://doi. org/10.1016/j.biomaterials.2013.07.036

25. Cardemil C, Elgali I, Xia W, Emanuelsson L, Norlindh B, Omar O, Thomsen P (2013) Strontium-doped calcium phosphate and hydroxyapatite granules promote different inflammatory and bone remodelling responses in normal and ovariectomised rats. PLoS One 8(12):e84932. https://doi.org/10.1371/journal.pone.0084932

26. Yang F, Yang D, Tu J, Zheng Q, Cai L, Wang L (2011) Strontium enhances osteogenic differentiation of mesenchymal stem cells and in vivo bone formation by activating $\mathrm{Wnt} /$ catenin signaling. Stem Cells 29(6):981-991. https://doi.org/10.1002/stem.646

27. Andersen OZ, Offermanns V, Sillassen M, Almtoft KP, Andersen IH, Sorensen S, Jeppesen CS, Kraft DC, Bottiger J, Rasse M, Kloss F, Foss M (2013) Accelerated bone ingrowth by local delivery of strontium from surface functionalized titanium implants. Biomaterials 34(24):5883-5890. https://doi.org/10.1016/j. biomaterials.2013.04.031

28. Fan YP, Chen XY, Chen Y, Yang GL, Wang HM, He FM (2016) Positive effect of strontium-oxide layer on the osseointegration of moderately rough titanium surface in non-osteoporotic rabbits. Clin Oral Implants Res 28:911-919. https://doi.org/10.1111/clr.12897

29. Park JW, Kwon TG, Suh JY (2013) The relative effect of surface strontium chemistry and super-hydrophilicity on the early osseointegration of moderately rough titanium surface in the rabbit femur. Clin Oral Implants Res 24(6):706-709. https://doi.org/10. 1111/j.1600-0501.2012.02444.x

30. Berglundh T, Stavropoulos A, Working Group 1 of the VIII European Workshop on Periodontology (2012) Preclinical in vivo research in implant dentistry. Consensus of the eighth European workshop on periodontology. J Clin Periodontol 39 (Suppl 12):15. https://doi.org/10.1111/j.1600-051X.2011.01827.x

31. Stavropoulos A, Becker J, Capsius B, Acil Y, Wagner W, Terheyden H (2011) Histological evaluation of maxillary sinus floor augmentation with recombinant human growth and differentiation factor-5-coated beta-tricalcium phosphate: results of a multicenter randomized clinical trial. J Clin Periodontol 38(10):966974. https://doi.org/10.1111/j.1600-051X.2011.01754.x

32. Oliveira GJ, Paula LG, Souza JA, Spin-Neto R, Stavropoulos A, Marcantonio RA (2016) Effect of avocado/soybean unsaponifiables on ligature-induced bone loss and bone repair after ligature removal in rats. J Periodontal Res 51(3):332-341. https://doi.org/10.1111/ jre. 12312

33. Park JW, Jang JH, Bae SR, An CH, Suh JY (2009) Bone formation with various bone graft substitutes in critical-sized rat calvarial defect. Clin Oral Implants Res 20(4):372-378

34. Aghaloo TL, Moy PK, Freymiller EG (2004) Evaluation of plateletrich plasma in combination with anorganic bovine bone in the rabbit cranium: a pilot study. Int J Oral Maxillofac Implants 19(1):5965

35. Schmitz JP, Hollinger JO (1986) The critical size defect as an experimental model for craniomandibulofacial nonunions. Clin Orthop Relat Res 205:299-308

36. Cooper GM, Mooney MP, Gosain AK, Campbell PG, Losee JE, Huard J (2010) Testing the critical size in calvarial bone defects: revisiting the concept of a critical-size defect. Plast Reconstr Surg 
125(6):1685-1692. https://doi.org/10.1097/PRS. 0b013e3181cb63a3

37. Peng S, Zhou G, Luk KD, Cheung KM, Li Z, Lam WM, Zhou Z, Lu WW (2009) Strontium promotes osteogenic differentiation of mesenchymal stem cells through the Ras/MAPK signaling pathway. Cell Physiol Biochem 23(1-3):165-174. https://doi.org/10. $1159 / 000204105$

38. Saidak Z, Marie PJ (2012) Strontium signaling: molecular mechanisms and therapeutic implications in osteoporosis. Pharmacol Ther 136(2):216-226. https://doi.org/10.1016/j.pharmthera.2012.07.009

39. Takaoka S, Yamaguchi T, Yano S, Yamauchi M, Sugimoto T (2010) The Calcium-sensing Receptor $(\mathrm{CaR})$ is involved in strontium ranelate-induced osteoblast differentiation and mineralization. Horm Metab Res 42(9):627-631. https://doi.org/10.1055/s-00301255091

40. Romer P, Desaga B, Proff P, Faltermeier A, Reicheneder C (2012) Strontium promotes cell proliferation and suppresses IL-6 expression in human PDL cells. Ann Anat= Anatomischer Anzeiger: official organ of the Anatomische Gesellschaft 194(2):208-211. https://doi.org/10.1016/j.aanat.2011.09.008

41. Li X, Zhou ZY, Zhang YY, Yang HL (2016) IL-6 contributes to the defective osteogenesis of bone marrow stromal cells from the vertebral body of the glucocorticoid-induced osteoporotic mouse. PLoS One 11(4):e0154677. https://doi.org/10.1371/journal.pone. 0154677
42. Poehling S, Pippig SD, Hellerbrand K, Siedler M, Schutz A, Dony C (2006) Superior effect of MD05, beta-tricalcium phosphate coated with recombinant human growth/differentiation factor-5, compared to conventional bone substitutes in the rat calvarial defect model. J Periodontol 77(9):1582-1590. https://doi.org/10.1902/ jop. 2006.050328

43. (EMEA) EMA (2005) Initial marketing authorization document Scientific Discussion

44. Dahl SG, Allain P, Marie PJ, Mauras Y, Boivin G, Ammann P, Tsouderos Y, Delmas PD, Christiansen C (2001) Incorporation and distribution of strontium in bone. Bone 28(4):446-453

45. Stavropoulos A, Wikesjo UM (2010) Influence of defect dimensions on periodontal wound healing/regeneration in intrabony defects following implantation of a bovine bone biomaterial and provisions for guided tissue regeneration: an experimental study in the dog. J Clin Periodontol 37(6):534-543. https://doi.org/10.1111/j. 1600-051X.2010.01566.x

46. Sartori S, Silvestri M, Forni F, Icaro Cornaglia A, Tesei P, Cattaneo V (2003) Ten-year follow-up in a maxillary sinus augmentation using anorganic bovine bone (Bio-Oss). A case report with histomorphometric evaluation. Clin Oral Implants Res 14(3):369372

47. Schlegel AK, Donath K (1998) BIO-OSS-a resorbable bone substitute? J Long-Term Eff Med Implants 8(3-4):201-209 